\title{
The carbon dioxide laser: an alternative surgery technique for the treatment of common cutaneous tumors in dogs
}

\author{
Joanna Paczuska ${ }^{1 *}$, Zdzisław Kiełbowicz ${ }^{1}$, Marcin Nowak ${ }^{2}$, Agnieszka Antończyk ${ }^{1}$, Rafał Ciaputa ${ }^{2}$ and Jakub Nicpoń ${ }^{1}$
}

\begin{abstract}
Background: Tumors of the skin and subcutaneous tissue are the largest group of canine neoplasms. Total excision is still the most effective method for treatment of these skin tumors. For its universal properties the carbon dioxide $\left(\mathrm{CO}_{2}\right)$ laser appears to be an excellent surgical instrument in veterinary surgery. Laser techniques are alternatives to traditional methods for the surgical management of tumors. The aim of this study was to compare various types of laser techniques in skin oncologic surgery: excision, ablation and mixed technique and to suggest which technique of $\mathrm{CO}_{2}$ laser procedure is the most useful in particular case of tumors in dogs.

Findings: The study was performed on 38 privately-owned dogs with total number of 40 skin tumors of different type removed by various $\mathrm{CO}_{2}$ laser operation techniques from 2010-2013. The treatment effect was based on the surgical wound evaluation, the relative time of healing and possible local recurrence of the tumor after 3 months post surgery. Local recurrence was observed in two cases. The study showed that in 30 cases time needed for complete resection of lesions was less than 10 minutes. Time of healing was longer than 12 days in 6 cases (42.8\%) with tumor excision and in 14 cases (87.5\%) where excision with ablation technique was performed.
\end{abstract}

Conclusions: The advantages of the $\mathrm{CO}_{2}$ laser surgery were better hemostasis, precision of working, non-contact dissection, less instruments at the site of operation and minimum traumatization of the surrounding tissues.

Keywords: $\mathrm{CO}_{2}$ laser surgery, Ablation, Skin tumors, Dogs

\section{Findings}

Laser light wavelength and frequency determine the way the laser light interacts with its target tissue. The carbon dioxide $\left(\mathrm{CO}_{2}\right)$ laser emits coherent, collimated and monochromatic beam of light at a wavelength of $10600 \mathrm{~nm}$. Wavelengths of laser light are highly absorbed by water followed by hemoglobin, melanin, and some proteins resulting in photothermal laser-tissue interaction [1]. High degree of absorption of $\mathrm{CO} 2$ laser light by water allows precise cutting of tissue via vaporization of the intra- and extracellular fluid and destruction of the cell membranes [2]. The $\mathrm{CO}_{2}$ laser can seal and coagulate small blood vessels (up to $0.5 \mathrm{~mm}$ ), lymphatics and nerve endings resulting in better visualization [3-6]. Non contact mode of

\footnotetext{
* Correspondence: jopaczuska@gmail.com

'Department of Surgery, Faculty of Veterinary Medicine, Wrocław University of Environmental and Life Science, pl. Grunwaldzki 51, 50-366 Wrocław, Poland Full list of author information is available at the end of the article
}

excision with laser can reduce intraroperative wound contamination by tumor cells [5].

The aim of this study was to compare different laser techniques in oncologic surgery of skin lesions: excision, ablation and mixed technique and to reveal the most useful $\mathrm{CO}_{2}$ laser technique for removal of skin tumors in dogs, depending on size, localization and malignancy.

Our study was conducted in the Surgery Department of Veterinary Medicine at the Wrocław University of Environmental and Life Sciences (Poland). Thirty-eight dogs with skin tumors were evaluated with 3-month follow-up after surgical treatment. The resection of the total number of 40 skin tumors of different types was performed (Table 1). The type of laser surgery technique used depended on localization, tumor size and suspected malignancy (Table 2). Excision was carried out in 14 cases, ablation in 10 cases, and mixed technique in 16 cases. All surgeries were performed with Eraser- $\mathrm{C} \mathrm{CO}_{2}$ laser with articulated arm delivery system. Choice of surgical technique 
Table 1 Number of tumor cases removed with $\mathrm{CO}_{2}$ laser depending on diameter, origin and malignancy

\begin{tabular}{llll}
\hline Diameter $[\mathbf{c m}]$ & $<\mathbf{0 . 5}$ & $\mathbf{0 . 5}-\mathbf{1 . 5}$ & $>\mathbf{1 . 5}$ \\
\hline Melanoma & $1(\mathrm{Mm})$ & $1(\mathrm{Mm})$ & 0 \\
Histiocytoma & 0 & $3(\mathrm{Mb})$ & $3(\mathrm{Mm})$ \\
Squamous cell carcinoma & $1(\mathrm{Nm})$ & $1(\mathrm{Nm})$ & $2(\mathrm{Nm})$ \\
Adenoma & $2(\mathrm{Nb})$ & $3(\mathrm{Nb})$ & $3(\mathrm{Nb})$ \\
Papilloma & $4(\mathrm{Nb})$ & $2(\mathrm{Nb})$ & 0 \\
Mastocytoma & 0 & $1(\mathrm{Mb})$ & $3(\mathrm{Mm})$ \\
Adenocarcinoma & 0 & $1(\mathrm{Nm})$ & $3(\mathrm{Nm})$ \\
Hemangioma & 0 & $1(\mathrm{Mb})$ & 0 \\
Fibroma & $4(\mathrm{Mb})$ & $1(\mathrm{Mb})$ & 0 \\
\hline
\end{tabular}

$M$ tumor of mesenchymal origin, $N$ tumor of epithelial origin, $b$ benign, $m$ malign.

and power settings were based on the surgeon's previous experience and references from other authors $[4,5]$.

Preanesthetic sedation was obtained with medetomidine $10 \mathrm{mg} / \mathrm{kg}$ body weight and butorphanol 0.2 to $0.4 \mathrm{mg} / \mathrm{kg}$ injected intramuscularly. For local anesthesia $2 \%$ lidocaine was used. When longer anesthesia was required intravenous injection of propofol at a dose of $2-5 \mathrm{mg} / \mathrm{kg}$ was administered.

Excision was made in 12 cases of tumors greater than $1.5 \mathrm{~cm}$ diameter, and 2 cases of tumors ranging from 0.5 to $1.5 \mathrm{~cm}$ in diameter. Prior to the incision, margins were marked using $4 \mathrm{~W}$ continuous wave $(\mathrm{CW})$ mode and $0.2 \mathrm{~mm}$ spot diameter (SD) guideline around the mass. Excision was performed using 8-12 W power output in $\mathrm{CW}$ mode and $0.2 \mathrm{~mm} \mathrm{SD}$. The skin margin was incised down to the subcutaneous tissue along the guiding line. During the excision the mass was retracted to ensure adequate tissue tension (Figure 1). To avoid collateral thermal tissue damage any char formation was removed with saline gauze. Vessels of a diameter above $1 \mathrm{~mm}$ were ligated with absorbable $3-0$ monofilament. To ensure that no untreated tissue had been left, a crosshatched pattern was used to cover areas of the tumor bed, with multiple passes of the $\mathrm{CO}_{2}$ laser beam in perpendicular directions with $4 \mathrm{~W}$ power output in CW mode and $0.4 \mathrm{~mm} \mathrm{SD}$. After excision, the post surgical wound was sutured with 3-0 absorbable monofilament with non-traumatic needle.

Ablation was made in 10 cases of neoplasm measuring less than $0.5 \mathrm{~mm}$ in diameter. The target tissue was painted and vaporized using 6-12 W, CW mode and 0.2- $0.4 \mathrm{~mm}$ SD. Char was wiped away. Ablation of underlying tissue

Table 2 Number of cases of $\mathrm{CO}_{2}$ laser surgery technique applied for resection of different size of cutaneous tumors

\begin{tabular}{llll}
\hline Diameter $[\mathrm{cm}]$ & $<\mathbf{0 . 5}$ & $\mathbf{0 . 5}-\mathbf{1 . 5}$ & $>\mathbf{1 . 5}$ \\
\hline Excision & 0 & 2 & 12 \\
Ablation & 10 & 0 & 0 \\
Excision with ablation & 2 & 12 & 2 \\
\hline
\end{tabular}

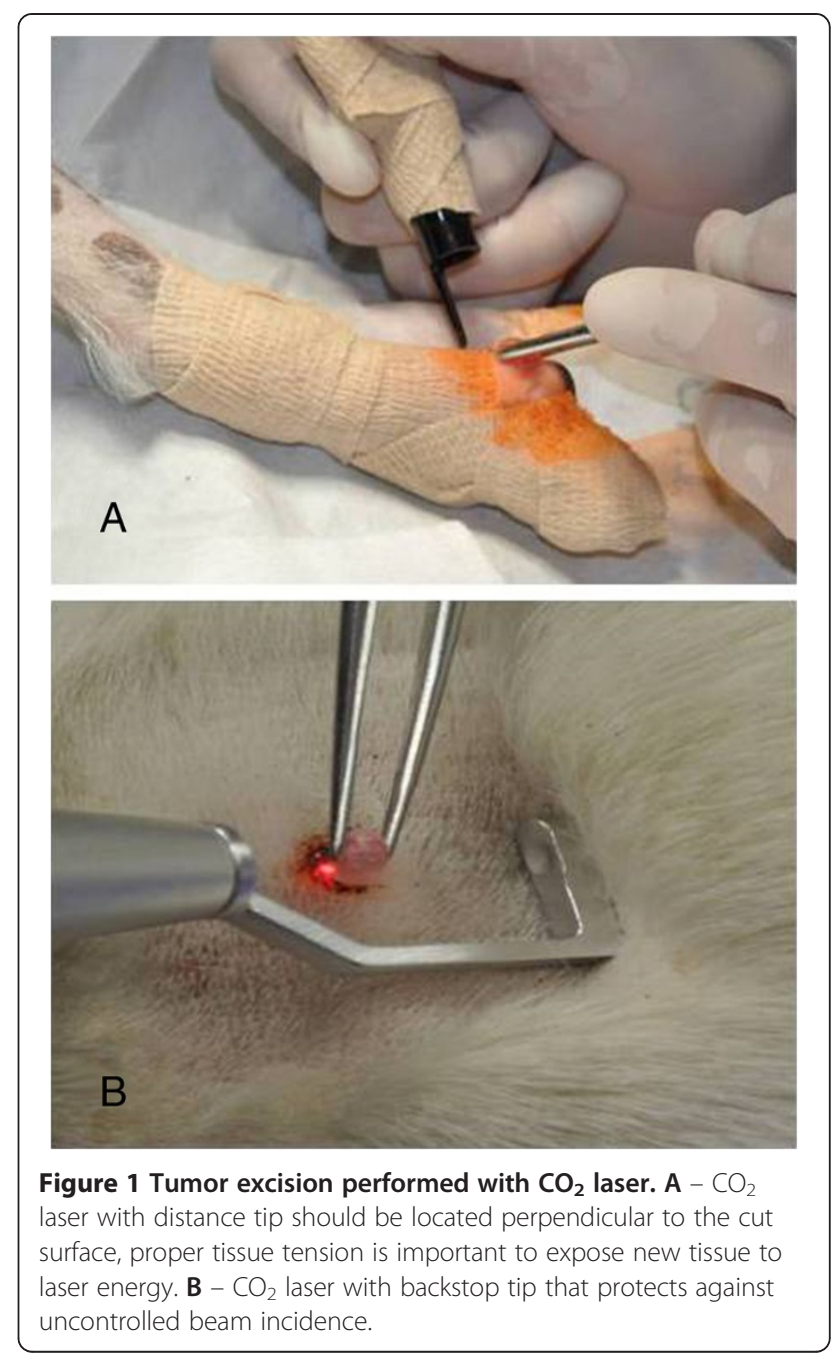

and a char wipe was repeated until total removal of the masses. The wound was left for second intention healing without suturing.

Mixed technique was administered in areas where total removal by excision was hard to achieve or biopsies for histopathological evaluation were required. Detachment of the tumor mass was maintained by excision with 8-12 W power output in CW mode and $0.2 \mathrm{~mm}$ SD. Underlying mass and $0.5 \mathrm{~mm}$ margins where ablated with CW mode setting ranging from 6-12 W power output and $0.4 \mathrm{~mm} \mathrm{SD}$.

Table 3 Time of procedure in groups with different surgery technique: ablation, excision and ablation with excision

\begin{tabular}{llll}
\hline $\begin{array}{l}\text { Time of } \\
\text { procedure [min] }\end{array}$ & Excision [\%] & Ablation [\%] & $\begin{array}{l}\text { Excision/ } \\
\text { Ablation [\%] }\end{array}$ \\
\hline$<3$ & 14.9 & 100.0 & 25.0 \\
$\mathbf{3 - 1 0}$ & 57.1 & 0 & 43.7 \\
$>\mathbf{1 0}$ & 28.0 & 0 & 31.3 \\
\hline
\end{tabular}



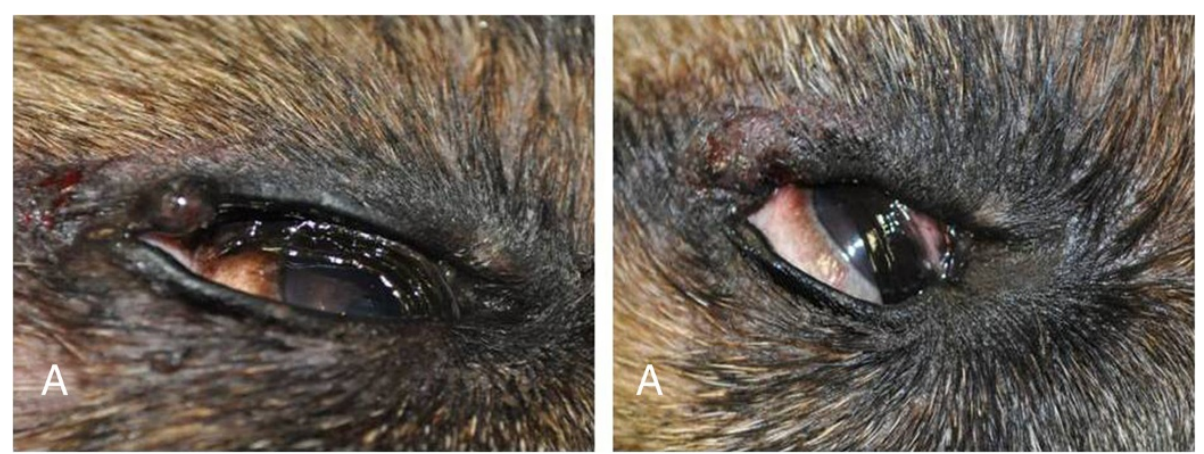

Figure 2 Meibomian gland tumor localized in the upper eyelid of an 11-yearsold German Shepherd. $\mathbf{A}$ - before $\mathrm{CO}_{2}$ laser ablation of the tumor. $\mathbf{B}$ - few minutes after $\mathrm{CO}_{2}$ laser ablation of the tumor.

Postsurgical evaluation of the wound was performed immediately after and at post-operative days 3,6 , and 12. The wound was evaluated for the presence of exudate or edema. The area of tumor extirpation was evaluated for local tumor recurrence after three months.

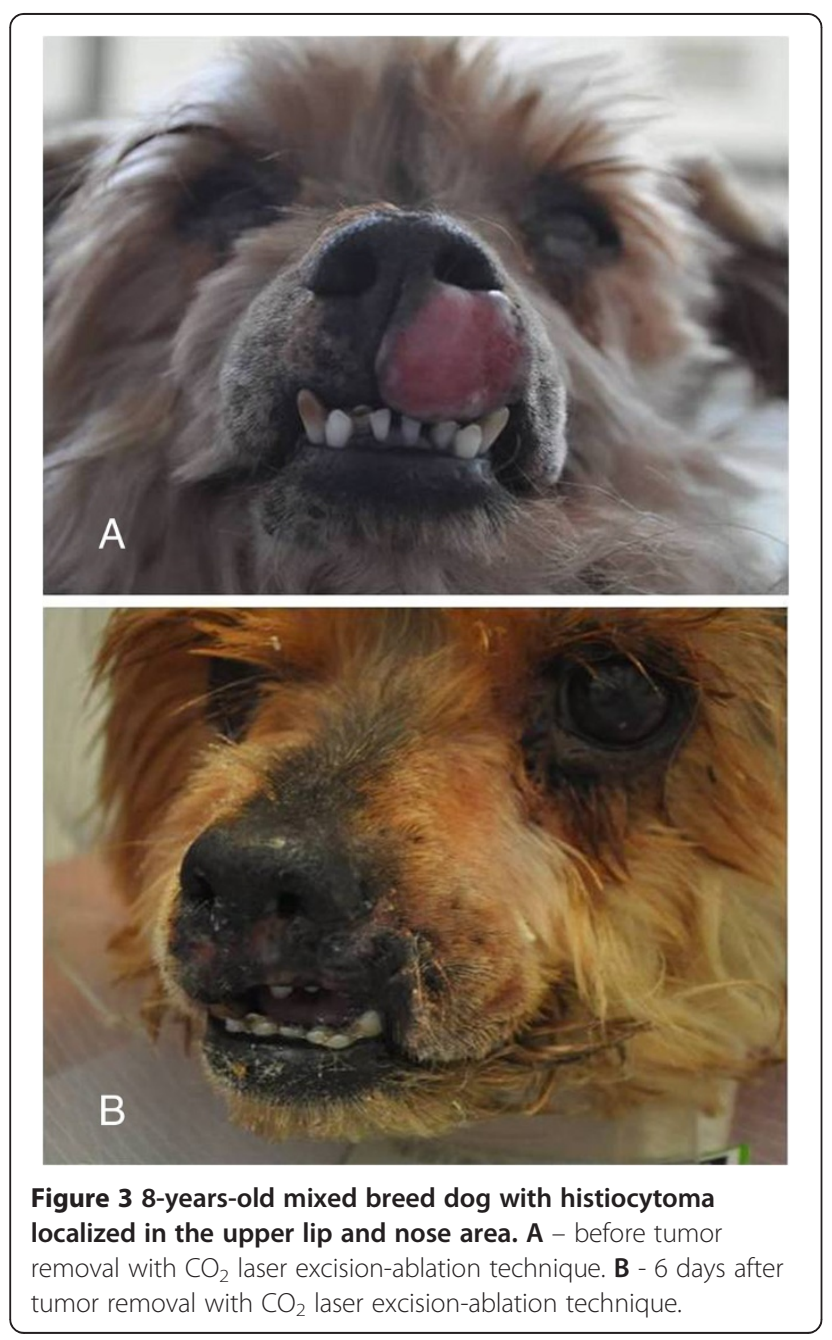

Total time needed for tumor removal in 16 cases was less than 3 minutes, in 14 cases between 3 and 10 minutes, and in 10 cases the surgery lasted more than $10 \mathrm{mi}-$ nutes (Table 3). Time of ablation was less than 3 minutes in all cases. The time needed to remove the tumor was dependent on its size and skills of the surgeon. In our study, the total time of the procedure was less than 10 min regardless of the technique used for $75 \%$ of cases.

In the group with tumors removed by surgical $\mathrm{CO}_{2}$ laser excision, the healing process in 6 cases (42.8\%) was longer than 12 days. Local recurrence has been observed in one patient with squamous cell carcinoma localized on the ear.

After tumor removal by ablation with $\mathrm{CO}_{2}$ surgical laser, the healing process was shorter than 12 days. No local recurrence was observed.

The healing process was longer than 12 days in 14 cases $(87.5 \%)$ after tumor removal by mixed operation technique. Local recurrence was found in one case of mastocytoma localized on the distal part of the hind leg.

The ablation technique was chosen only in cases of tumor size less than $0.5 \mathrm{~cm}$, when wide margins of excision weren't required or possible to maintain, such as masses localized on the eyelid (Figure 2). $\mathrm{CO}_{2}$ ablation is useful in all cases of small benign lesions. Ablative techniques should be considered only when complete excision with clean margins is not possible [5].

Excision with $\mathrm{CO}_{2}$ laser is a very useful surgery technique in cases of larger tumors when margins of resection

Table 4 Prevalences of exudation and edema after tumor resection with different laser surgery technique

\begin{tabular}{|c|c|c|c|c|c|c|}
\hline & \multicolumn{2}{|c|}{ EXCISION } & \multicolumn{2}{|c|}{ ABALTION } & \multicolumn{2}{|c|}{ EXCISON/ABLATION } \\
\hline & $\begin{array}{l}\text { Edema } \\
{[\%]}\end{array}$ & $\begin{array}{l}\text { Exudation } \\
\text { [\%] }\end{array}$ & $\begin{array}{l}\text { Edema } \\
{[\%]}\end{array}$ & $\begin{array}{l}\text { Exudation } \\
{[\%]}\end{array}$ & $\begin{array}{l}\text { Edema } \\
{[\%]}\end{array}$ & $\begin{array}{l}\text { Exudation } \\
{[\%]}\end{array}$ \\
\hline Day 0 & 21.4 & 0 & 20.0 & 0 & 43.8 & 0 \\
\hline Day 3 & 7.1 & 35.7 & 0 & 20.0 & 12.5 & 56.3 \\
\hline Day 6 & 0 & 28.6 & 0 & 0 & 0 & 12.5 \\
\hline Day 12 & 0 & 7.1 & 0 & 0 & 0 & 0 \\
\hline
\end{tabular}


and histological evaluation of the excised tissue are required. Excision of all abnormal tissue may be applied as readily as they do to conventional surgery [7]. Improved visibility through better hemostasis provides greater confidence of complete excision and time saving.

Excision with ablation technique is useful when excision with wide margins is not possible (Figure 3). Excision with ablation was used to remove masses localized on limbs, eyelid, nose, lip and ears, particularly in cases of malignant tumors such as melanoma, squamous cell carcinoma, and mastocytoma with uncertainty about complete excision of all neoplastic cells.

Proper laser surgery technique with adequate power density delivered to the target tissue has a very important influence on thermal damage to adjacent structures and consequently on wound healing [2,7]. An average zone of thermal damage after laser incision in soft tissues is $<0.6 \mathrm{~mm}[2,8,9]$. General effects of laser on soft tissues are correlated with the delivered amount of energy or power density, which is determined by laser power outage (watts) divided by the laser tip spot size $\left(\mathrm{cm}^{2}\right)$. A thin layer of char is surrounded by an area of coagulative necrosis which is removed during the normal healing by exudation. Larger zones of reversible edema and inflammation develops within minutes or hours post surgery but later resolves [6]. In our study edema occurred in most cases on the day of surgery (Table 4). Postsurgical exudation and edema in patients operated with excision-ablation technique was higher than in other groups. Most probably it is related to the time of exposure on laser light and consequently higher risk of thermal damage of surrounding tissues. Excessive peripheral thermal tissue effects may delay or create abnormal wound healing with increasing the possible risk of incisional dehiscence [4]. Wound healing delay is caused by temporary postponement of inflammation, phagocytic resorption, collagen production and re-epithelization in the early stages of repair [10]. Ablation was performed in cases when diameter of tumor did not exceed $0.5 \mathrm{~cm}$. The time of exposure to the laser beam and consequently the risk of thermal injury was the lowest among the patients which explains the shortest time of healing in this group. Difference between extended time of healing between groups with excision and excision with ablation may also be caused by longer exposure to the laser beam.

The basic principles of wide excision and removal of all abnormal tissue margins with $\mathrm{CO}_{2}$ laser should be the same as with conventional surgery technique $[5,6]$. During the 3-month post surgical observation period we noticed local recurrence only in two cases. Lanzafame et al. [11] demonstrated fewer recurrences after $\mathrm{CO}_{2}$ laser tumor removal compared to conventional scalpel excision. The probable cause of this difference is the sealing of small blood vessels and lymph vessels by the $\mathrm{CO}_{2}$ laser which prevents tumor cells spreading [3-5]. Moreover, both the no-touch surgery technique and the coagulation zone can reduce intraoperative wound contamination by malignant tumor cells what may result in decreasing recurrence risk.

Laser operation techniques by excision, ablation or excision with ablation provide better hemostasis, precision of working, non-contact dissection, less instruments at the site of operation and minimal traumatization of the surrounding tissues and an opportunity to reduce or eliminate risk of tumor recurrence. Good results of treatment depend on appropriate selection of technique adjusted to the particular case.

\section{Abbreviations}

$\mathrm{CO}_{2}$ : Carbon dioxide; CW: Continuous wave; SD: Spot diameter.

\section{Competing interests}

The authors declare that they have no competing interests exist.

\section{Authors' contributions}

The study was designed by all authors. JP and JN did the surgery procedures and drafted the manuscript. ZK coordinated editing and revision of the manuscript. AA took pictures and anesthetized patients, MN and RC performed histopathological evaluation of the tumors and margins. All authors have read and approved the final version of the manuscript.

\section{Author details}

${ }^{1}$ Department of Surgery, Faculty of Veterinary Medicine, Wrocław University of Environmental and Life Science, pl. Grunwaldzki 51, 50-366 Wrocław, Poland. ${ }^{2}$ Division of Pathomorphology and Veterinary Forensics, Department of Pathology, Faculty of Veterinary Medicine, Wrocław University of Environmental and Life Science, ul. C.K.Norwida 31, 50-375 Wrocław, Poland.

Received: 23 July 2013 Accepted: 3 January 2014

Published: 7 January 2014

\section{References}

1. Katzir A: Lasers and optical fibers in medicine. San Diego: Academic; 1993.

2. Wilder-Smith P, Arrastia A-M, Liaw L-H, Berns M: Incision properties and thermal effects of three $\mathrm{CO} 2$ lasers in soft tissue. Oral Surg Oral Med Oral Pathol Oral Radiol Endod 1995, 79:685-691.

3. Bartels KE: Lasers in veterinary medicine-where have we been, and where are we going? Vet Clin Small Anim 2002, 32:495-515.

4. Berger N, Eeg PH: Veterinary laser surgery a practical guide. lowa: Blackwell Publishing; 2006

5. Holt TL, Mann FA: Soft tissue application of lasers. Vet Clin Small Anim 2002, 32:569-599.

6. Hernandez-Divers SJ: Radiosurgery and laser in zoological practice: separating fact from fiction. J Exot Pet Med 2008, 17:165-174.

7. Palmer SE: Treatment of common cutaneous tumors using the carbon dioxide laser. Clin Tech Equine Pract 2002, 1:43-50.

8. Fitzpatrick RE, Ruiz-Esparza J, Goldman MP: The depth of thermal necrosis using the $\mathrm{CO} 2$ laser: a comparison of the superpulsed mode and conventional mode. J Dermatol Surg Oncol 1991, 17:340-344.

9. Nelson JS, Berns MW: Basic laser physics and tissue interactions. Contemp Dermatol 1998, 2:3-15.

10. Hendrick DA, Meyers A: Wound healing after laser surgery. Otolaryngol Clin North Am 1995, 28:969-986.

11. Lanzafame RJ, McCormack CJ, Rogers DW, Naim JO, Herra HR, Hinshaw JR: Mechanisms of reduction of tumor recurrence with carbon dioxide laser in experimental mammary tumors. Surg Gynecol Obstet 1988, 167:493-496.

doi:10.1186/1751-0147-56-1

Cite this article as: Paczuska et al:: The carbon dioxide laser: an alternative surgery technique for the treatment of common cutaneous tumors in dogs. Acta Veterinaria Scandinavica 2014 56:1. 